\title{
Incidence of asthma in female Swedish hairdressers
}

\author{
M Albin, L Rylander, Z Mikoczy, L Lillienberg, A Dahlman Höglund, J Brisman, \\ K Torén,B Meding, K Kronholm Diab, J Nielsen
}

Occup Environ Med 2002;59:1 19-123

See end of article for authors' affiliations

Correspondence to: Dr M Albin, Department of Occupational and Environmental Medicine, Lund University Hospital, SE-221 85 Lund, Sweden; maria.albin@ymed.lu.se

Accepted 27 July 2001

\begin{abstract}
Objective: To investigate the risk of asthma in hairdressers.
Methods: The incidence of asthma was retrospectively estimated in a Swedish nationwide study including all female hairdressers certified from vocational schools from 1970 to 1995, and a stratified sample of women from the general population were referents. A postal questionnaire included questions on respiratory tract symptoms, atopy, smoking, working periods as a hairdresser, and number of specific hair treatments performed/week. Reported exposures were validated by occupational hygienists. Rate ratios of incidence (IRRs) of asthma were estimated by Poisson regression, adjusted for calendar year of observation, hay fever, smoking, and region of domicile.

Results: The crude incidences of asthma/1000 person-years were: 3.9 during active years as a hairdresser, 2.8 among the hairdressers when not working in the profession, and 3.1 among the referents. The corresponding IRR for being an active hairdresser compared with the referents was $1.3195 \%$ confidence interval $(95 \% \mathrm{Cl}) 1.0$ to 1.6). Moderate effects on risk of asthma were found both from hairdressing work (IRR=1.6 (1.1 to 2.2) among never-smokers) and from smoking (IRR=1.6 (1.2 to 2.2) among referents). However, the combined effect from hairdressing work and smoking (IRR=1.5 (1.0 to 2.1) was less than expected $(p=0.02)$. No effect modification by respiratory atopy was found. The hairdressers most often performing hair bleaching treatments (IRR=1.5 (0.7 to 3.0)) or using hair spray (IRR=1.4 (0.8 to 2.4)) had, compared with the most infrequent users, a slightly, but not significantly higher incidence of asthma. Exposure to persulphates in hair bleach was estimated to be 0.04-0.15 $\mathrm{mg} / \mathrm{m}^{3}$ during mixing of the powder. Reported average number of bleaching treatments agreed well with those performed according to a diary.

Conclusions: Active hairdressing work was associated with a moderately increased incidence of asthma among lifelong non-smokers. The results are moderately supportive, but not conclusive, of associations between asthma and exposure to hair bleach or hair spray.
\end{abstract}

$\mathrm{H}$ airdressers are exposed to several reactive agents with potentially irritant and sensitising effects on the airways. Several case studies on airway symptoms in hairdressers, mostly asthma, ${ }^{1-7}$ have been published, but only a few epidemiological studies. ${ }^{8-11}$ These indicate an increased risk for development of asthma among hairdressers. However, these studies (except Leino et $a l^{10}$ ) are based on few exposed cases or hospital based materials. The European Community Respiratory Health Survey (Kogevinas et al ${ }^{12}$ and M Kogevinas; personal communication) found no excess in the prevalence of asthma symptoms or medication among hairdressers. Thus, reliable risk estimates are few and inconsistent. Also the interaction with personal risk factors such as atopy and smoking is unknown.

Among possible aetiological agents in hairdressers' asthma, the main focus has been on the persulphates used in bleaching powder, ${ }^{125-813}$ but their quantitative contribution to asthma is not known.

We have performed a nationwide study including all Swedish hairdressers certified from 1970 to 1995 . They were investigated by a postal questionnaire on exposure and symptoms. The aims of the study were to investigate the incidence of asthma during work as a hairdresser, especially relative to exposure to bleaching powder and hair spray, and effect modification by atopy and smoking.

\section{SUBJECTS AND METHODS}

\section{Hairdressers}

In Sweden, since 1970 there has been a 3 year training for hairdressers. Usually the training starts at the age of 15 or 16. The third year was spent practising in hairdressing salons until 1993 when practice was organised at the school.

\section{Main messages}

- A moderately increased asthma risk was found among female non-smoking hairdressers.

- The risk was slightly, but not significantly, higher for the hairdressers that were most often performing hair bleaching treatments or using hair spray.

- A moderately increased risk of asthma was found from smoking.

- Surprisingly, the risk of developing asthma among hairdressers who smoked was not higher than among women who either worked as a hairdresser or smoked.

- Atopy did not modify the risk from hairdressing work.

From the records of all 29 vocational schools for hairdressers in Sweden, a cohort of female hairdressers born in 1946 or later and who graduated from 1970 to 1995 was established. Altogether 7204 women were identified.

A questionnaire was posted in December 1996. After two reminders 4849 (67\%) returned the questionnaires. Reliable data for one or more variables were missing in 892 of the returned questionnaires. Most of these had missing data for several important variables. Thus 3957 hairdressers remain as participants in the final calculations. Descriptive data for participants and non-participants are given in table 1.

Abbreviations: IRR, incidence rate ratio 
Table 1 Descriptive data for the cohort of female hairdressers and a cohort of women from the general population (referents)

\begin{tabular}{|c|c|c|c|c|c|c|}
\hline \multirow[b]{3}{*}{ Variable } & \multicolumn{3}{|l|}{ Hairdressers } & \multicolumn{3}{|l|}{ Referents } \\
\hline & \multirow[b]{2}{*}{$\begin{array}{l}\text { Participants } \\
\mathrm{n}=3957\end{array}$} & \multicolumn{2}{|c|}{ Non-participants } & \multirow[b]{2}{*}{$\begin{array}{l}\text { Participants } \\
n=4905\end{array}$} & \multicolumn{2}{|c|}{ Non-participants } \\
\hline & & All $n=3247$ & $\begin{array}{l}\text { Interviewed } \\
n=393\end{array}$ & & All $n=2450$ & $\begin{array}{l}\text { Interviewed } \\
n=134\end{array}$ \\
\hline Year of birth (median (range)) & $\begin{array}{l}1966 \\
(1946-77)\end{array}$ & $\begin{array}{l}1964 \\
(1946-78)\end{array}$ & $\begin{array}{l}1966 \\
(1946-77)\end{array}$ & $\begin{array}{l}1965 \\
(1946-78)\end{array}$ & $\begin{array}{l}1967 \\
(1946-78)\end{array}$ & $\begin{array}{l}1965 \\
(1946-78)\end{array}$ \\
\hline Year of certification (median (range)) & $\begin{array}{l}1987 \\
(1970-95)\end{array}$ & $\begin{array}{l}1985 \\
(1970-95)\end{array}$ & $\begin{array}{l}1987 \\
(1970-95)\end{array}$ & - & - & - \\
\hline Region (\%, south/middle-north) & $49.8 / 50.2$ & $44.2 / 55.8$ & $45.8 / 54.2$ & $46.3 / 53.7$ & $42.9 / 57.1$ & $50.0 / 50.0$ \\
\hline Hay fever (\%, yes/no) & $24.0 / 76.0$ & - & - & $25.5 / 74.5$ & - & - \\
\hline Smoking $(\%$, ever/never) & $50.0 / 50.0$ & - & $52.4 / 47.6$ & $45.7 / 54.3$ & - & $52.2 / 47.8$ \\
\hline Childhood eczema (\%, yes/no) & $16.0 / 84.0$ & - & $13.7 / 86.3$ & $21.0 / 79.0$ & - & $17.9 / 82.1$ \\
\hline
\end{tabular}

\section{Referents}

As referents 7355 women randomly selected from the general Swedish population in 1996, stratified for age and restricted to the year of birth between 1946 and 1978 were identified. After two reminders 5569 (76\%) returned the questionnaire. Among the returned questionnaires reliable data for one or more variables were missing in 664, thus 4905 participated in the final calculations (table 1 ).

\section{Questionnaire}

\section{Asthma}

All women were asked if they had or had had asthma and about the year of onset of the disease. A follow up question asked if the diagnosis was confirmed by a physician.

\section{Common risk factors}

Information about smoking, hay fever with onset before the age of 18, and childhood eczema was also asked for in the questionnaire. Moreover, the place of residence in 1996 was known for all participants. The distributions of these variables are presented in table 1 .

\section{Exposure}

The hairdressers were asked to state the calendar years of all employments as a hairdresser from the time they graduated. They also stated if they for some reason were not working as a hairdresser for periods of more than a year. For each employment, the number of times specific preformed categories of treatments with bleaching powder and hair spray were performed was asked.

\section{Non-responders}

To study the incidence of asthma among non-responders, 589 out of the 2355 hairdressers and 224 out of the 1786 referents (about one fourth and one eighth, respectively) that had not returned the questionnaire were randomly selected. They were contacted in 1998 by a letter in which they were informed that a nurse would later interview them by phone about symptoms and exposure. Altogether, 393 hairdressers (67\%) and 134 referents ( $60 \%$; table 1 ) were interviewed by telephone. The most common reasons for not performing an interview were: not being listed with a phone number (95 hairdressers (16\%) and 47 referents $(21 \%)$ ) and refusal to participate (65 hairdressers (11\%) and 23 referents $(10 \%))$.

In the telephone interview, based on a questionnaire, hairdressers were asked about periods of employment as hairdressers. Everybody answered questions about asthma and when the symptoms appeared. Also, they were asked about smoking and childhood eczema. The wording of the questions was the same as in the postal questionnaire.

\section{Validation of exposure}

We examined the reliability in self reported exposure among the hairdressers by comparing answers of this study to those given 3 years later in another study where a subsample $(n=1038)$ of the hairdressers participated. The same treatments were asked for in both questionnaires, but the answers

Table 2 Asthma incidence rate ratios (IRRs) with $95 \% \mathrm{Cls}$ in a cohort of active female hairdressers and in a cohort from the general female population (referents), respectively, obtained from multivariate models

\begin{tabular}{|c|c|c|c|c|c|c|c|c|}
\hline \multirow[b]{2}{*}{ Variable } & \multicolumn{4}{|c|}{ Hairdressers* } & \multicolumn{4}{|c|}{ Referents† } \\
\hline & Cases & $\begin{array}{l}\text { Person- } \\
\text { year }\end{array}$ & $\begin{array}{l}\text { Incidence } \\
\text { (/1000) }\end{array}$ & IRR $\ddagger(95 \% \mathrm{Cl})$ & Cases & $\begin{array}{l}\text { Person- } \\
\text { year }\end{array}$ & $\begin{array}{l}\text { Incidence } \\
\text { (/1000) }\end{array}$ & IRR $\ddagger(95 \% \mathrm{CI})$ \\
\hline \multicolumn{9}{|l|}{ Calendar year: } \\
\hline $1970-80$ & 6 & 3477 & 1.7 & $1.0(-)$ & 12 & 11932 & 1.0 & $1.0(-)$ \\
\hline 1981-90 & 36 & 11548 & 3.1 & 1.8 (0.8 to 4.3$)$ & 78 & 27978 & 2.8 & 2.8 (1.5 to 5.1$)$ \\
\hline 1991-96 & 62 & 11704 & 5.3 & 3.1 (1.3 to 7.3$)$ & 112 & 24643 & 4.5 & 4.7 (2.6 to 8.6$)$ \\
\hline Total & 104 & 26729 & 3.9 & & 202 & 64553 & 3.1 & \\
\hline \multicolumn{9}{|l|}{ Hay fever: } \\
\hline No & 41 & 20791 & 2.0 & $1.0(-)$ & 65 & 51104 & 1.3 & $1.0(-)$ \\
\hline Yes & 63 & 5939 & 10.6 & 5.5 (3.7 to 8.1$)$ & 137 & 13449 & 10.2 & 8.0 (6.0 to 10.8$)$ \\
\hline \multicolumn{9}{|l|}{ Smoking: } \\
\hline Never & 54 & 12173 & 4.4 & $1.0(-)$ & 80 & 31780 & 2.5 & $1.0(-)$ \\
\hline Ever & 50 & 14556 & 3.4 & $0.9(0.6$ to 1.3$)$ & 122 & 32773 & 3.7 & 1.6 (1.2 to 2.2 ) \\
\hline \multicolumn{9}{|l|}{ Region: } \\
\hline South & 48 & 13983 & 3.4 & $1.0(-)$ & 78 & 30035 & 2.6 & $1.0(-)$ \\
\hline Middle-north & 56 & 12747 & 4.4 & $1.2(0.8$ to 1.8$)$ & 124 & 34518 & 3.6 & 1.3 (1.0 to 1.8 ) \\
\hline
\end{tabular}


Table 3 Effects of cohort affiliation (active female hairdressers and referents, respectively) and smoking on incidence rate ratio (IRR) $(95 \% \mathrm{Cl})$ of asthma

\begin{tabular}{|c|c|c|c|c|}
\hline \multirow[b]{3}{*}{$\begin{array}{l}\text { Cohort } \\
\text { affiliation }\end{array}$} & \multicolumn{4}{|l|}{ Smoking } \\
\hline & Never & & Ever & \\
\hline & $\begin{array}{l}\text { Incidence } \\
(/ 1000)\end{array}$ & IRR* $(95 \% \mathrm{CI})$ & $\begin{array}{l}\text { Incidence } \\
(/ 1000)\end{array}$ & IRR* $(95 \% \mathrm{CI})$ \\
\hline Referents & 2.5 & $1.0(-)$ & 3.7 & $\begin{array}{l}1.6 \\
(1.2 \text { to } 2.2)\end{array}$ \\
\hline Hairdressers & 4.4 & $\begin{array}{l}1.6 \\
(1.1 \text { to } 2.2)\end{array}$ & 3.4 & $\begin{array}{l}1.5 \\
(1.0 \text { to } 2.1)\end{array}$ \\
\hline
\end{tabular}

*IRRs are adjusted for calendar year (1970-80, 1981-90, and 1991-96), hay fever (no/yes), and region (south/middle-north).

were given in preformed categories in the first study, and in absolute numbers in the second.

Furthermore, a random sample of 19 salons, stratified by the number of hairdressers in the cohort still working there, was selected from one major city (Gothenburg) and the surrounding region to validate the exposure information. Two occupational hygienists visited the salons during the high and low season, asked the hairdressers to fill in the questionnaire again, and also asked them to complete a diary for 3 weeks stating the number of different treatments each day. Personal and stationary measurements of air concentrations of persulphate were made twice at one salon with 20 employees, using IOM samplers with cellulose acetate filters. The filters were analysed at the Regional Institute for Occupational Health in Tampere, Finland. The detection limit was $1.5 \mu \mathrm{g}$ persulphate/ filter.

\section{Statistics}

Effects of common risk factors on incidence of asthma Rate ratios of incidence of asthma (IRR) with 95\% confidence intervals (95\% CIs) were estimated by a Poisson regression with EGRET software (Statistics and Epidemiology Research Corporation, Seattle). The referents, followed up from 18 years of age, were used to determine the effects of common risk factors on incidence of asthma. Age (six categories; <20, 20-24, $25-29,30-34,35-39$, and $\geqslant 40$ years) had no effect (not in table), whereas the incidence of asthma increased during the period of observation (three categories; 1970-80, 1981-90, and 1991-6). Both hay fever and childhood eczema had an effect, but the effect of childhood eczema almost disappeared $($ IRR $=1.2$ (95\% CI 0.9 to 1.6$))$ when hay fever was simultaneously included in a multivariate model. A slightly increased incidence of asthma was found among women who were ever smokers and among women living in the middle and northern regions of the country. The final model thus included calendar year of observation, hay fever, smoking, and region (table 2). The estimated univariate effects were, apart from childhood eczema, similar to the estimates obtained from the multivariate model.

\section{Estimation of incidence of asthma among hairdressers}

Hairdressers without previous asthma were followed up from the year of certification, usually at the age of 18. Also, the incidence of asthma was calculated only during exposed time - that is, time not working as a hairdresser was excluded. The effect on incidence of asthma of bleaching (three categories; $0-1,2-7$, and $\geqslant 8$ treatments/week) and using hair spray (three categories; $0-30,31-50$, and $\geqslant 51$ treatments/week) was evaluated during exposed time.

\section{RESULTS}

\section{Asthma incidence}

The crude incidence of asthma among the hairdressers was 3.5/1000 person-years (not in table), whereas a higher
Table 4 Effect of spraying and bleaching, respectively, on asthma incidence in a cohort of active female hairdressers. Asthma incidence rate ratios (IRRs) with $95 \% \mathrm{Cls}$ are shown

\begin{tabular}{|c|c|c|c|c|}
\hline Exposure & Cases & $\begin{array}{l}\text { Person- } \\
\text { year }\end{array}$ & $\begin{array}{l}\text { Incidence } \\
\text { (/1000) }\end{array}$ & IRR* $(95 \% \mathrm{CI})$ \\
\hline \multicolumn{5}{|l|}{ Model I: } \\
\hline \multicolumn{5}{|c|}{ Spraying (treatments/week): } \\
\hline $0-30$ & 24 & 7807 & 3.1 & $1.0(-)$ \\
\hline $31-50$ & 38 & 10457 & 3.6 & 1.1 (0.7 to 1.8$)$ \\
\hline$\geqslant 51$ & 31 & 6619 & 4.7 & $1.4 \dagger(0.8$ to 2.4$)$ \\
\hline \multicolumn{5}{|l|}{ Model II: } \\
\hline \multicolumn{5}{|c|}{ Bleaching (treatments/week): } \\
\hline $0-1$ & 30 & 8816 & 3.4 & $1.0(-)$ \\
\hline $2-7$ & 57 & 14419 & 4.0 & $1.1(0.7$ to 1.8$)$ \\
\hline$\geqslant 8$ & 10 & 2105 & 4.7 & $1.5 \ddagger(0.7$ to 3.0$)$ \\
\hline
\end{tabular}

*IRRs in the models are adjusted for calendar year (1970-80 1981-90, and 1991-96), hay-fever (no/yes), smoker (never/ever), and region (south/middle-north); †spraying, test for trend $p=0.23$;

$\ddagger$ bleaching, test for trend $p=0.31$

incidence was found when only years in active hairdressing work was assessed (3.9/1000 person-years, table 2). There was a small difference between the incidence of asthma in the cohort of hairdressers when years not working as a hairdresser were assessed (2.8/1000 person-years, not in table) and that among the referents (3.1/1000 person-years, table 2$)$.

Hairdressers who did not answer the questionnaire (non-participants) reported a slightly higher incidence of asthma according to the phone interview overall (4.9/1000 person-years based on 20 cases) and during active work as hairdressers (6.0/1000 person-years based on 16 cases) than the participants. Non-participating referents also reported a slightly higher incidence of asthma (4.9 per 1000 person-years based on 18 cases) than the participants.

The median time from certification to the onset of asthma was 6 years among the hairdressers. Change of work due to asthma was reported by 29 hairdressers $(0.7 \%)$ and 34 referents $(0.7 \%)$.

\section{Effects of work as a hairdresser}

A moderate cohort effect of being an active hairdresser compared with the referents $(\mathrm{IRR}=1.3$ (1.0 to 1.6), not in table) was found. The effect was, however, modified by smoking (table 3). Thus, we found an effect of being a hairdresser on the incidence of asthma among the lifelong non-smokers, and an effect of smoking in the referents. A negative effect modification $(p=0.02)$ was indicated by the absence of a further increase in risk during smoking and hairdressing.

\section{Validation of exposure}

In the subsample of hairdressers who answered the same questions twice, 46 had reported the highest category of treatments/week $(\geqslant 8)$ in the first questionnaire, but for the same calendar year only 14 of them reported a similar number in the second questionnaire ( $\kappa$ value 0.24 ). The corresponding figures for use of hair spray were 112 and 17 in the highest category ( $\kappa$ value 0.17 ). Thus, the comparisons indicated a fair to poor agreement. ${ }^{14}$

However, the average number of bleaches performed/week according to the diary agreed with the interval stated in the questionnaire among 13 out of 15 hairdressers. The use of hair spray was generally overestimated in the questionnaire compared with the diaries both during the high and low seasons (one category by nine hairdressers, two categories by three hairdressers; correct category three hairdressers).

Personal sampling (three samples) during mixing of bleaching powder with peroxide and application of the mixture gave $15-49 \mu \mathrm{g}$ persulphate $/ \mathrm{m}^{3}$ for sampling periods of 


\section{Policy implications}

- Our study, and those of others, indicate an increased risk of asthma in hairdressers, with exposure to persulphates, and possibly also hair spray as the main causal agents.

- Detectable persulphate concentrations in air were found only during mixing, and not during application. We suggest:

- A change from powder to less dusty (paste or granulate) preparations of hair bleach.

- Installation of exhaust ventilation in the mixing areas, and improvement of the general ventilation in the salons.

- That an occupational aetiology is considered when asthma is diagnosed in a hairdresser.

32-135 minutes. Stationary sampling (four samples) in the mixing area over 200-319 minutes gave <4-6.1 $\mu \mathrm{g}$ persulphates $/ \mathrm{m}^{3}$. No detectable concentrations were found at application. To be able to receive detectable amounts of persulphates 5-7 mixings of bleaching powder and peroxide were performed during each sampling period. The mixing of bleaching powder takes $2-5$ minutes for each treatment. If it is anticipated that the exposure to persulphates occurs mainly during the mixing periods ( 5 minutes/mixing) with almost zero exposure during application the exposure during mixing would be $35-150 \mu \mathrm{g}$ persulphate $/ \mathrm{m}^{3}$ and in the mixing area $<23-50 \mu \mathrm{g}$ persulphate $/ \mathrm{m}^{3}$.

\section{Effects from specific exposures}

Among the hairdressers, the incidence of asthma was slightly higher in the most frequent users of bleaching products than in the others, but the difference was not significant (table 4). As in the earlier analyses, the univariate effect estimates were quite close to those in the full model. For the use of hair spray, the pattern was similar to that for the bleaching productsthat is, the most frequent users had a moderately nonsignificantly increased incidence of asthma compared with the others.

\section{DISCUSSION}

The salient finding in our study was an increased incidence of asthma among the hairdressers, corresponding to one extra case/1000 person-years. The effect was modified by smoking, and evident only among lifelong non-smokers. A stronger effect, corresponding to two extra cases/1000, was suggested (but not significant) in hairdressers who often used spray or bleaching products.

The validation of reported number of treatments in the questionnaire, compared with diaries, indicated that hair bleach treatments were correctly reported, whereas the hair spray treatments were overestimated. Comparisons of answers in the two questionnaires were not firmly conclusive due to different contexts and designs of the questions, but indicate that the agreement was poor to fair, and thus misclassification may have introduced a bias which is most likely to underestimate the effects of specific exposures.

Experimentally, hair bleach induces airway hyperresponsiveness in rabbits after a single short term (4 hours) exposure to concentrations of persulphates of around $5-10 \mathrm{mg} / \mathrm{m}^{3} .{ }^{15} \mathrm{We}$ found a mean persulphate exposure during mixing and application $10-700$ times lower $\left(0.015-0.49 \mathrm{mg} / \mathrm{m}^{3}\right)$. The estimated exposure during the mixing periods was 35-250 times lower $\left(0.04-0.15 \mathrm{mg} / \mathrm{m}^{3}\right)$. Stationary sampling close to the clients during bleaching treatments showed no detectable air concentrations. In a clinical study of hairdressers, hair bleach and the use of aerosol hair spray were the most provocative factors to increase the respiratory symptoms, and $90 \%$ of the diagnosed occupational respiratory diseases were judged to be caused by persulphates in bleaches. ${ }^{16}$ Our study is weakly supportive of a causal role for hair spray and bleaches in hairdressers' asthma, but it is not conclusive.

The excess rate of asthma in hairdressers in this study is close to that in a Finnish study $\left(0.9 / 1000^{10}\right)$ with a similar design, but substantially higher than the rates of reported occupational asthma in hairdressers both in Sweden (0.13/ $\left.1000^{17}\right)$ and in Italy $\left(0.20 / 1000^{11}\right)$. The time from certification to the onset of asthma (median 6 years) was longer than among workers handling laboratory animals (mean 2-3 years), ${ }_{18}^{18}$ but similar to that reported in bakers (mean 6.5 years).$^{19}$

Several selective processes may be important among the hairdressers. Sensitive subjects are likely to be selected out of training, tending to give conservative risk estimates, but unfortunately it was not possible for us to identify those who entered the training. It is also likely that young girls with asthma and eczema are advised not to enter the training. Thus, a selection away from dermal atopy was present in the cohort of hairdressers, but it was no longer clearly associated with asthma when hay fever was included in the model. Although the prevalence of hay fever was similar in responders in the two cohorts, the prevalence of childhood asthma was lower among the hairdressers $(2.4 \%)$ than among the referents $(3.9 \%)$, showing that a selection against more serious respiratory atopy had taken place. Residual confounding between the cohorts is probably present if a selection by severity of disease has been operating within the hay fever group also, as we could not adjust for this.

We had a fairly low response rate to our questionnaire, especially among the hairdressers. We considered the possibility of a selective participation by interviews with the non-participants. A slightly higher proportion of the nonparticipants than the participants were ever smokers or had dermal atopy. These two variables were determinants of higher risk of asthma among the participants, and we found accordingly a slightly higher incidence of asthma among nonparticipants than participants in both cohorts. As the participation rate was lower among the hairdressers, this is most likely to lead to a weak underestimation of the difference between the two cohorts.

Accurate information about asthma and the year of onset is important in this study. Self reports about asthma assessed by questionnaire have been shown to be reliable and have a good specificity, especially for age groups below 50 years. ${ }^{20}$ We limited our study to these age groups. The sensitivity is moderate, and selective for severity of the disease. ${ }^{21}$ This should give an underestimation of the incidence, especially for mild disease, but the high specificity makes it adequate for comparisons of rates. In the present study the proportions of subjects reporting asthma who had been diagnosed by a physician were high, and similar in hairdressers and referents, but higher among smokers (hairdressers $85 \%$, referents $87 \%$ ), than among nonsmokers (hairdressers $73 \%$, referents $73 \%$; not in results).

In a former study of bakers' asthma, which used a similar approach, Brisman and Järvholm ${ }^{19}$ found that when answering a questionnaire on the year of onset of asthma a second time, $47 \%$ gave the same year and another $32 \% \pm 1$ year of the first answer. The incidence of asthma during unexposed time in the hairdressers' cohort was similar to the one among the referents, indicating an acceptable comparability between the two cohorts and no substantial misclassification between exposed and unexposed years.

Time trends are well established for childhood asthma, but have been less studied for asthma of adult onset. However, an increasing trend also for adult asthma has been indicated in some studies. ${ }^{22-25}$ Also, regional differences have been found with, for instance a higher prevalence in northern than southern Sweden. ${ }^{26}$ We found a strong effect of calendar year of observation, and a moderate effect of region of living, but within our span of 18-49 years of age we found no effect of 
age. The effect of calendar-year could also to some extent be due to differential recall for different periods.

We found the expected strong effect on risk of asthma from hay fever as a marker of respiratory atopy in both cohorts, ${ }^{24} 27$ but no modification of the cohort effect by respiratory atopy. This is in agreement with overall findings for occupational asthma by Kogevinas et al. ${ }^{9}$

The higher proportion of subjects with asthma diagnosed by a physician among smokers than non-smokers in both cohorts may indicate a selective underreporting among the smokers, and thus that the effect on risk of asthma from smoking is underestimated. However, such a differential reporting in smokers and non-smokers should not introduce interaction with exposure, as it was the same in the two cohorts. Furthermore, quantitative smoking habits were not considered in our main analyses, and could, if substantially different between the two cohorts, have confounded our findings. However, a strong bias is not likely, as median age at the start of smoking was 16 years in both cohorts (not in results). Also, the fraction of women among the hairdressers who stopped smoking were $51 \%$, at a median age of 25 years, and the corresponding figures among the referents were 52\% and 26 years. Moreover, the distributions of cigarettes smoked/day were almost the same in both cohorts. Overall, a moderate effect of smoking was found, similar to earlier reports. ${ }^{27}{ }^{28}$

However, we found an interaction between smoking and work as a hairdresser, for which we presently have no explanation. It has been stated that in occupational settings, current smokers have a higher risk of developing sensitisation to high molecular weight agents, whereas non-smokers have a higher risk for developing asthma due to low molecular weight compounds. ${ }^{29}$ If so, our findings would fit into this. The biological background for such a possible pattern is not known. If hairdressers' asthma is induced by irritants and not an IgE sensitising process, it is possible that the proportion of people susceptible to developing asthma in the population is limited, and thus once one risk factor is operating, addition of another does not increase the risk.

\section{ACKNOWLEDGEMENTS}

The study was funded by the Swedish Council for Work Life Research, the Swedish Foundation for Health Care Sciences and Allergy Research, and by the Medical Faculty Lund University. Gunborg Lindahl assisted with the collection of the cohort, and Karin Amilon, and Ingrid Lindqvist, with the interviews with the non-participants. Anders Holmén, assisted in editing the questionnaire for scanning. Gudrun Persson, Gunnel Nilsson, Monica Hansi, Helena Brönmark and Ulrika Wallin handled the questionnaires. Anna Axmon and Ann-Kathrine Alveblom supplied us with exposure information from a subsample who also participated in another study.

\section{Authors' affiliations}

M Albin, L Rylander, Z Mikoczy, K Kronholm Diab, J Nielsen, Department of Occupational and Environmental Medicine, Lund University Hospital, SE-221 85 Lund, Sweden

L Lillienberg, A Dahlman Höglund, J Brisman, K Torén, Institute of Internal Medicine, Section of Occupational Medicine, Sahlgrenska University Hospital, SE-412 66 Göteborg, Sweden

K Torén, Department of Respiratory Medicine and Allergology,

Sahlgrenska University Hospital, SE-413 45 Göteborg, Sweden

B Meding National Institute for Working Life, SE-1 1279 Stockholm, Sweden

\section{REFERENCES}

1 Gamboa PM, de la Cuesta CG, Garcia BE, et al. Late asthmatic reaction in a hairdresser, due to the inhalation of ammonium persulphate salts. Allergol Immunopathol (Madr) 1989;17:109-11.
2 Pankow W, Hein $\mathrm{H}$, Bittner $\mathrm{K}$, et al. Persulphate asthma in hairdressers. Pneumologie 1989;43:173-5.

3 Schwartz HJ. Effect of chronic chromolyn sodium therapy in a beautician with occupational asthma. J Occup Med 1989:31:112-4.

4 Aubart JF, Ameille J. Une nouvelle cause d'allergie respiratoire chez les coiffeurs: la poudre de lycopode. Arch Mal Prof 1991;52:515-6.

5 Parra FM, lgea JM, Quirce $S$, et al. Occupational asthma in a hairdresser caused by persulphate salts. Allergy 1992;47:656-60.

6 Schwaiblmair M, Vogelmeier C, Fruhmann G. Occupational asthma in hairdressers: results of inhalation tests with bleaching powder. Int Arch Occup Environ Health 1997;70:419-23.

7 Macchioni P, Kotopulos C, Talini D, et al. Asthma in hairdressers: a report of 5 cases. Med Lav 1999;90:776-85.

8 Blainey AD, Ollier S, Cundell D, et al. Occupational asthma in a hairdressing salon. Thorax 1986;41:42-50.

9 Kogevinas $M$, Anto JM, Soriano JB, et al. The risk of asthma attributable to occupational exposures. A population-based study in Spain. Spanish Group of the European Asthma Study. Am J Respir Crit Care Med 1996;154:137-43

10 Leino T, Tammilehto L, Paakkulainen $\mathrm{H}$, et al. Occurrence of asthma and chronic bronchitis among female hairdressers. A questionnaire study. J Occup Environ Med 1997;39:534-9.

11 Bena A, D'Errico A, Mirabelli D. A system for the active surveillance of occupational bronchial asthma: the results of 2 years of activity of the PRiOR program. Med Lav 1999:90:556-71.

12 Kogevinas M, Antó JM, Sunyer J,et al. Occupational asthma in Europe and other industrialised areas: a population-based study. Lancet 1999;353: 1750-4

13 Hytönen $M$, Leino T, Sala $E$, et al. Nasal provocation test in the diagnostics of hairdressers' occupational rhinitis. Acta Otolaryngol Suppl 1997:529: 133-6

14 Altman DG. Practical statistics for medical research. London: Chapman and Hall, 1992.

15 Mensing T, Marek W, Raulf-Heimsoth M, et al. Acute exposure to hair bleach causes airway hyperresponsiveness in a rabbit model. Eur Respir J 1998;12:1371-4

16 Leino T, Tammilehto L, Hytönen $M$, et al. Occupational skin and respiratory diseases among hairdressers. Scand J Work Environ Health 1998:24:398-406.

17 Torén K. Self reported rate of occupational asthma in Sweden 1990-2. Occup Environ Med 1996;1 1:757-61.

18 Gordon S, Newman Taylor AJ. Animal, insect and shellfish allergy. In: Bernstein L, Chan-Yeung M, Malo HL, et al, eds. Asthma in the workplace. New York: Marcel Dekker, 1999:399-424.

19 Brisman SJ, Järvholm BG. Occurrence of self reported asthma among Swedish bakers. Scand J Work Environ Health 1995;21:487-93.

20 Torén K, Brisman J, Järvholm B. Asthma and asthma-like symptoms in adults assessed by questionnaires. A literature review. Chest 1993:104:600-8.

21 Tunsäter A, Palmqvist $M$, Balder $B$, et al. Asthma-deniers versus those confirming asthma - is there a difference in lung function or degree of medication? [Abstract.] Eur Respir J 1999;14(suppl 30);487.

22 Reijula K, Haathela T, Klaukka T, et al. Incidence of occupational asthma and persistent asthma in young adults has increased in Finland. Chest 1996;110:58-61

23 Sunyer J, Anto JM, Tobias A, et al. Generational increase of self reported first attack of asthma in 15 industrialised countries. European Community Respiratory Health Study (ECHRS). Eur Respir J 1999:14:885-91.

24 Huovinen E, Kaprio J, Laitinen LA, et al. Incidence and prevalence of asthma among adult Finnish men and women of the Finnish twin cohort from 1975 to 1990 , and their relation to hay fever and chronic bronchitis. Chest 1999:115:928-36.

25 Upton MN, McConnachie A, McSharry C, et al. Intergenerational 20 year trends in the prevalence of asthma and hay fever in adults: the Midspan family study surveys of parents and offspring. $B M$ 2000:321:88-92.

26 Lindström $M$, Lundbäck $B$, Larsson $M$, et al. Still a north-south gradient in prevalence of respiratory symptoms in Sweden [abstract]. Eur Respir J 2000;16(suppl 31):111

27 Torén K, Hermansson BA. Incidence rate of adult onset asthma in relation to age, sex, atopy, and smoking: a Swedish population based study of 15813 adults. Int J Tuberc Lung Dis 1999:3:192-7.

28 Chen Y, Dales R, Krewski D, et al. Increased effects of smoking and obesity on asthma among female Canadians: the National Population Health Survey, 1994-5. Am J Epidemiol 1999;150:255-62.

29 Chan-Yeung M, Malo JL. Natural history of occupational asthma. In: Bernstein L, Yeung M, Malo HL, et al, eds. Asthma in the workplace. New York: Marcel Dekker, 1999;129-43. 